\title{
InvestiCreación artística identidad y perspectivas
}

Dra. Irma Fuentes Mata

Correo: ifuentesmata@msn.com

Dr. Pablo Parga Parga

INBA /CENIDIAP

Universidad Autónoma de Querétaro

Recibido para su publicación: 30 de agosto de 2015

Aprobado: 01 de octubre de 2015

Está ponencia es el resultado de una reflexión sobre la importancia del vínculo investigación-creación, realizada por dos docentes con más de veinte años de experiencia en la formación de artistas en escuelas profesionales de nivel superior. Si bien durante los últimos años ha empezado a preocupar en el ámbito académico del arte la incorporación de actividades de investigación que justifiquen las horas académicas, es cierto que las condiciones para realizar dicha tarea tienen que ver no sólo con lo que se hace, sino cómo, porqué y para qué se realiza una investigación en el proceso de creación y formación artística.

En el pasado, cuando las profesiones artísticas no se consideraban licenciaturas o posgrados, los artistas no aspiraban a justificar determinadas actividades académicas, sus aspiraciones se centraban en "ser artistas", no en ser licenciados, maestros o doctores. Estaban enfocados en aprender "el oficio" o la "profesión", adquirir experiencia, circular en los medios propicios para el mercado del arte, exponer, participar o interpretar determinados personajes, o encontrar un mecenas -aunque fuera institucionalque le patrocinara su producción. Su capacidad de crear involucraba muchas competencias y/o saberes que necesariamente incluían procesos metodológicos complejos, entre los cuales estaba la investigación, llamada a veces "Alquimia del Arte", también existía un saber al que Foucault define como:

[...] conjunto de elementos formados de manera regular por una práctica discursiva y que son indispensables a la constitución de una ciencia, aunque no estén necesariamente destinados a darle lugar, se le puede llamar saber. Un saber es aquello de lo que se puede hablar en una práctica discursiva que así se encuentra especificada: el dominio constituido por los diferentes objetos que adquirirán o no un estatuto científico [....] Existen saberes que son independientes de las ciencias (que no son ni su esbozo histórico ni su reverso vivido), pero no existe saber sin una práctica discursiva definida; y toda práctica discursiva puede definirse por el saber que forma (Foucault 2010:237-238).

Quienes pretendían ser artistas y, por otro lado, quienes disfrutaban o consumían la obra, tenían muy claro cuáles eran los centros formadores prestigiosos, dónde estaban localizados y qué méritos se tenían que poseer para ingresar a dichas instituciones y mantenerse en ellas, más allá de los criterios que hoy en día emiten los comités certificadores, evaluadores y acreditadores.

Alain Touraine nos comenta en La crítica a la modernidad que la noción de sociedad para designar un conjunto concreto, definido por fronteras, por fuentes reconocidas de autoridad, por órganos de aplicación de leyes y por una conciencia de pertenencia, recibió pues en aquel pensamiento social clásico otro sentido, un sentido explicativo y no descriptivo, puesto que la sociedad y la posición que uno ocupa en su seno son elementos de explicación de la conducta humana y de su evaluación. Y este sociologismo es un elemento central de la visión modernista (2000:25).

Pero desde hace casi treinta años las cosas cambiaron, al final de los años setenta y durante los primeros años de la década de los ochenta, cuando una serie de profesiones humanísticas y del arte se "elevaron" al nivel de Licenciatura, las artes entraron a las universidades y se tuvo que homologar al sistema de contratos, reconocimientos y estímulos para la docencia, difusión e investigación las funciones sustantivas de cualquier universidad. En ese momento, la creación no fue considerada para nivel superior, de ahí que para aspirar a éste hubiera dos caminos: hacer otra licenciatura ajena al arte o formarse en planes "sin el grado". Fue entonces cuando numerosos artistas se esforzaron por incorporarse al sistema homologado del Instituto Politécnico Nacional atendiendo las exigencias académicas de instituciones con otras vocaciones. 
Los artistas que durante años crearon coreografías, que entrenaron años para interpretar a un personaje, que realizaron obra plástica, que compusieron obras musicales, que montaron espectáculos teatrales en los que eran intérpretes consagrados y que habían estudiado en escuelas nacionales o internacionales, no lograron nivelarse a las licenciaturas que ahora les exigía el sistema, pues sus propios programas de formación no ofrecían el nivel. Para subsanar el problema del grado académico, en el año de 1987 el Instituto Nacional de Bellas Artes instrumentó programas de Regularización Profesional en acuerdo con la Secretaría de Educación Pública (Acuerdo 125 de SEP) para reconocer la experiencia y dedicación de los creadores que por décadas habían formado a numerosas generaciones y que, sin embargo, les era muy difícil cubrir con todas las exigencias de las instituciones de nivel superior. Lo que ellos representaban en el lienzo o en el escenario hubo que traducirlo a textos; las composiciones a la historia de la música; la obra plástica en crítica del arte o metodología y manuales de procedimientos y así, la creación empezó a hablar con el lenguaje de la investigación y a tratar de forzar su propio campo profesional a una terminología distante de su proceso original.

El artista creador tuvo que aprender otro lenguaje, no sólo el del área artística sino ahora el de la literatura, la historia, la filosofía, la psicología, la antropología, la administración, la planeación o todas aquellas disciplinas que sí podían "demostrar" objetivamente y en términos académicos, científicos, técnicos y metodológicos el conocimiento generado por la creación. Pierre Bordieu nos explica:

El discurso científico llama a una lectura científica, capaz de reproducir las operaciones de las que él mismo es producto. No obstante, las palabras del discurso científico, y en particular aquellas que designan a las personas (los nombres propios) o instituciones ( el Collège de France son exactamente las del discurso ordinario, las de la novela o la historia, mientras que los referentes de estas dos especies de discurso están separados por toda la distancia que introduce la ruptura y la construcción científica (2009:35-36).
Actualmente, al interior de las universidades, conforme a las características que definen el perfil de los docentes en la educación superior como profesores-investigadores, los creadores adscritos a facultades o unidades académicas de Artes (o de Bellas Artes) realizan una jornada extra, pues regularmente no se les valida la creación como investigación. En esta situación, los creadores- profesores se ven obligados a investigar desde disciplinas (científicas o sociales) ajenas a las artes, haciendo a un lado su proyecto artístico como creadores o intérpretes. En casos excepcionales, se les valida la creación, pero están obligados a disfrazar su proyecto de creación como si fuese de investigación. Lo que parecería una solución, en realidad representa la validación de un sistema hegemónico que valora más la investigación que la creación. Respecto a dicha validación, Chalmers al analizar la teoría de Feyerabend sostiene que:

[ ...] El falso supuesto de que hay un modelo científico universal al que deberían ajustarse todas las formas de conocimiento desempeña un papel perjudicial en nuestra sociedad aquí y ahora. Especialmente a la luz del hecho de que la versión del método científico a la que normalmente se recurre es una tosca versión empirista o inductivista. Esto es especialmente aplicable al campo de la teoría social, en el que se defienden en el nombre de la ciencia teorías que sirven para manipular aspectos de nuestra sociedad a un nivel superficial (investigación de mercado, psicología conductista) en lugar de comprenderla y ayudarnos a cambiarla a un nivel más profundo (1982:198).

Aunado a lo anterior, y ante el tsunami certificador que valida más los grados académicos que la calidad en la producción artística, es fácil vislumbrar un futuro poco alentador para las artes prácticas, pues cada vez la actividad creadora de los docentes artistas pasa a un segundo o tercer plano. La ecuación parece sencilla: entre más alto se aspire al grado académico menos tiempo habrá para ejercer la práctica artística. Este remedo de ecuación sobrevivirá mientras no se validen como posgrados los niveles de perfeccionamiento artístico. De seguir en la misma ruta que ahora se perfila, tendremos muchos investigadores del arte, muchos teóricos del arte, pero pocos artistas que 
enseñen arte y que realicen creación artística. En este sentido, la tesis de esta ponencia invita a reconocer que si bien los protocolos de investigación y creación pueden compartir aspectos o categorías comunes, habría que establecer la diferencia entre los procesos metodológicos y los productos, ya que un creador -en su proceso artístico- realiza investigación sin necesidad de un protocolo, mientras que el investigador utiliza el protocolo como punto de partida para el desarrollo de su investigación y en algunas ocasiones ello lo conduce a la creación.

En el proceso de construcción de este campo híbrido de la InvestiCreación Artística, el término designa los procesos de incubación, exploración, interpretación, proyección, significación y fijación intrínsecos a la creación artística. Para su análisis, hemos propiciado el encuentro de Cuerpos Académicos de Arte y Cultura intentando recuperar la experiencia de cada una de las áreas artísticas, así como la vinculación interdisciplinaria a partir del trabajo de docentes, investigadores, creadores de arte, miembros y colaboradores de la Red de InvestiCreación Artística en un espacio denominado Seminario de investigación, formación y creación artística.

En este espacio de colaboración, construcción conceptual y creación multidisciplinaria de académicos del Instituto Nacional de Bellas Artes y Cuerpos Académicos de la Universidad Autónoma de Querétaro, la Universidad Autónoma de Zacatecas y la Universidad Michoacana de San Nicolás de Hidalgo, vinculados a partir de dicha Red, registrada en Programa de Mejoramiento del Profesorado, (Promep ahora Prodep) se desarrolla el Seminario de Investigación de manera permanente e itinerante en las ciudades de Querétaro, Morelia y Zacatecas, el cual permitió la realización del III Congreso Internacional de Artes y Humanidades La InvestiCreación Artística en 2012. Posteriormente se produjo el trabajo artístico multidisciplinario "Peregrino: Rutas y Ramas de Hugo Gutiérrez Vega" sustentado en la InvestiCreación Artística y se han realizado otros espectáculos como "Pasaporte con estrellas" de Emilio Carballido y "El Viaje de los Cantores" de Hugo Salcedo, en diferentes formatos, espacios escénicos y radiofónicos.
La InvestiCreación Artística es un término acuñado por quienes exponemos el presente trabajo para identificar los procesos de generación de conocimiento en el campo de las humanidades y las artes, en específico, los procesos desarrollados por los creadores que cumplen tres funciones sustantivas en las Instituciones de Educación Superior: la docencia, la investigación ligada a la creación y la difusión; esta última entendida en su dimensión precisa por ser justamente el proceso que comunica la creación. La dinámica que actualmente se propicia en las Instituciones de Educación Superior es que los profesores nos sólo estén en sus aulas transmitiendo, aplicando, compartiendo, o divulgando conocimiento, sino que en la mayoría de las universidades se les exije que sean productores, generadores, o creadores de conocimiento. Estos atributos se han malentendido ubicándolos sólo en la investigación. Sin embargo, los profesores del campo del arte generan un cúmulo de conocimientos necesarios e indispensables para realizar su labor profesional, pero ya que mucho de ese saber, aunque no todo, está dentro de las competencias "practicas", no ha sido conocido ni reconocido en su justa medida.

Las instancias ordenadoras y financiadoras del saber científico y tecnológico han trabajado durante años por consolidar su campo y para ello han sistematizado con mucho detenimiento los procesos, modelos, enfoques, medios, materiales y productos que se pueden lograr en el campo de la investigación científica. Ante ello, organismos como el CONACYT han dado reconocimiento a todas esas actividades, incluso han abierto sus márgenes a otros campos del conocimiento como las Humanidades y las Artes (organizadas en el Área IV) en el Sistema Nacional de Investigadores, cuyos espacios son ocupados por académicos que se desarrollan en el campo de las ciencias sociales, algunas veces en humanidades y pocas veces en las artes. Pero generalmente se debe cumplir al pie de la letra con las exigencias que se marcan desde un modelo de la investigación. Así, aquellos profesores que aspiran a ser reconocidos se esfuerzan inútilmente por generar un tipo de saber para el que no fueron preparados, o del que no forman parte, o que está ajeno a su práctica profesional. Para ello, invier- 
ten horas en generar productos académicos mermando el tiempo para la producción artística o literaria.

Por otro lado, si bien existe el Sistema Nacional de Creadores o los apoyos destinados a la creación, desde organismos como el CONACULTA o las áreas estatales de cultura, los requerimientos y procedimientos de registro a planes o proyectos de trabajo artístico no necesariamente estipulan explicitar los procesos de investigación.

Un avance importante en la mayor parte de las instituciones de educación artística de educación superior es la equivalencia que se hace de los docentes que forman parte del Sistema Nacional de Creadores con los que forman parte del Sistema Nacional de Investigadores. Sin embargo, resulta insensata esta equivalencia, pues el referente es el Sistema Nacional de Investigadores. Bajo esta perspectiva, habría que reconocer la especificidad de cada perfil, no donde uno sea el referente del otro.

Frente a este panorama, los integrantes de la Red de InvestiCreación Artística nos propusimos reflexionar sobre los aspectos que involucran la creación para la investigación y la investigación para la creación. Si bien los autores de esta ponencia sostuvimos acalorados debates, reconocimos que el proceso es muy complejo, con múltiples aristas y varias perspectivas y líneas posibles de acción para la reflexión.

Al cabo de las reuniones del seminario-taller identificamos que cada universidad tiene una forma distinta de plantear los protocolos de investigación, de formular los requisitos y características para validar la investigación y de reconocerla. En algunas universidades -las más afortunadas- el catálogo de resultados o productos de la investigación permite incluir productos artísticos. Identificamos, también, que cada institución reconoce dentro de los procesos de promoción del personal docente y los estímulos alguna actividad vinculada a la creación pero generalmente traducida a la difusión.

Un producto colectivo da cuenta de esta diversidad con respecto a cómo se investiga en las artes. Investigar el Arte. Testimonios, protocolos y proyectos de investigación artística (2015) es un estudio en donde se aborda el problema de la conceptualización y la práctica de la investigación realizada por los creadores artísticos en general y en particular por los creadores integrados como profesores o docentes en las universidades. El libro está publicado y consta de 15 participaciones de autores especialistas en música, teatro, danza, artes visuales y educación artística.

Finalmente, consideramos que el campo de la InvestiCreación Artística es un campo de conocimiento en proceso de construcción; es un reto para aquellos que quieren seguir produciendo arte y conocimiento como un vínculo indisociable. Los frentes en los que debemos luchar para continuar siendo creadores y/o investigadores de arte tienen que enfrentarse a sistemas institucionales, sociales, y de evaluación y debemos construir un lenguaje que mantenga la esencia del arte sin doblegarse a otro tipo de saber y sin perder su originalidad, aunque por el momento naveguemos en los dos barcos.

\section{Bibliografía}

Bordieu, Pierre (2009) Homo Academicus. Siglo XXI Editores, México.

Bachelard, Gastón (2007) La formación del espíritu científico. Contribución al psicoanálisis del conocimiento objetivo. Siglo XXI Editores, México.

Chalmers, Alan F. (1982) ¿Qué es esa cosa llamada ciencia? Una valoración de la naturaleza y el estatuto de la ciencia y sus métodos. Siglo XXI Editores, México.

Foucault, Michel (2010) La arqueología el saber. Siglo XXI Editores, México.

Foucault, Michel (2010) Las palabras y las cosas una arqueología de las ciencias humanas. Siglo XXI Editores, México.

Touraine, Alain (2000) Crítica a la Modernidad. Fondo de Cultura Económica México. 